\title{
Bone Marrow Involvement in Non-Hematological Malignancy: A Clinico-pathological Study From a Tertiary Hospital
}

\author{
Farah JalalyMeenai, Sandeep Ojha*, Manal A. Ali, Rubal Jain and NilimaSawke \\ Department of Pathology \&Chirayumedial college and hospital, Bhopal, India
}

\begin{abstract}
Background: Bone marrow is an important site for metastasis in cases of non hematological malignancies and is routinely performed to stage the disease or to rule out metastasis in suspected cases..

Purpose: Purpose of the study is to evaluate bone marrow in cases of solid tumors and also to enumerate the types of tumors metastasizing to marrow at our institute.

Methods; This was a retrospective study and clinical and laboratory data were retrieved from case files and laboratory records. All the case where bone marrow aspirate was performed to rule out metastasis or for staging were included along with those cases where patient presented to us with hematological abnormalities and diagnosed to have a metastasis in marrow.

Results: Out of total 758 cases of total bone marrow performed, 89 were performed in proven cases of non hematological malignancies of which 31 showed tumor deposits. While in two cases metastatic deposits were first seen in marrow aspirate. Most common tumor metastasizing to marrow at our institute was adenocarcinoma of lung followed by breast and small cell carcinoma of lung. In pediatric age group most common tumor was Ewing's sarcoma followed by rhabdomyosarcoma. Most common peripheral smear abnormality seen was thrombocytopenia followed by anemia and leukoerythroblastic blood picture.
\end{abstract}

Conclusion: Bone marrow aspiration is an easy, rapid and sensitive technique to determine metastasis of solid tumors in bone marrow and can be performed in hematological abnormalities to rule out any metastasis in otherwise unsuspected cases.

Keywords: Bone Marrow Metastasis, Non Hematological Malignancies, Bone Marrow Aspiration, Hematological Findings.

\section{Introduction}

Bone marrow $(\mathrm{BM})$ is one of the common and important sites to be involved by solid tumors. Presence of metastasis in bone marrow can alter the clinical course of disease by changing the stage and also hampering the clinical condition of the patient by suppressing the valuable blood components. BM examination is done in cases of non hematological malignancies in order to stage the disease or to know the involvement. Detection of the metastasis in bone marrow is very important as it may affect the clinical course, treatment, and overall prognosis of the disease. ${ }^{[1]}$

Any tumor that metastasizes via blood may deposit in BM.BM involvement may be suspected in cases of solid tumors presenting with bone pains, pathological fractures, radiological findings and unexplained hematological abnormalities etc. However, BM involvement may also be asymptomatic.

Most common solid tumors which metastasize to marrow in adults are carcinoma of the prostate, breast and lung. And in pediatric age group neuroblastoma, rhabdomyosarcoma, Ewing's sarcoma and retinoblastoma are the major tumors metastasizing to $\mathrm{BM}^{[2-4]}$.
Bone marrow may be involved focally in cases of non hematopoietic malignancies. According to many studies $\mathrm{BM}$ biopsy was found to be more sensitive than aspirate to identify metastasis. ${ }^{[2]}$ Thus, BM aspirate must be performed along with trephine biopsies in order to satisfactorily exclude marrow metastasis. ${ }^{[2,5]}$

This study was performed at a tertiary care cancer hospital in central India and aims at analyzing the BM involvement in cases of non hematological malignancies and their presentation in hematological abnormalities.

\section{Material \& Method}

This was a retrospective study performed over a period of 3 year duration (2013 to 2016). Data of the patients retrieved from laboratory and clinical records. The cases which were included in the study either had a known primary with suspected metastasis or cases where BM was performed for staging in asymptomatic cases. This study also includes cases where BM was performed for unexplained hematological abnormalities and metastasis was detected on BM examination. Hematological malignancies like lymphoma and Hodgkin's disease were not included in this study. Bone marrow aspiration was studied along with 
biopsy wherever available to find the presence of tumor in them and then positive and negative metastasis were made.

Iliac crest was used to aspirate bone marrow and slides were stained by Leishman stain. The bone marrow biopsies were obtained by Jamshidi needle $(8 \mathrm{Gx} 10 \mathrm{~cm})$ and were fixed in $10 \%$ formalin solution. These biopsies were then transferred to Gooding and stewart fluid in order to decalcify the bony bit. After decalcification, these were routinely processed and paraffin blocks were prepared. Approximately 3-4 micrometer sections were taken and stained with hematoxylin -eosin.

\section{Results}

During this study period of 3 year, bone marrow examination was performed in 758 patients for various reasons and of these 91 cases were of solid tumors. Out of this, 89 cases had aknown non-hematopoietic malignancies and bone marrow aspiration was performed to stage the disease. Two cases presented with unexplained thrombocytopenia with leukoerythroblastic picture and found to have metastatic deposits of carcinoma on bone marrow examination. Of these 91 cases BM aspirate was performed on a total of 20 pediatriccases $(<18$ years) and 71 adults. BM biopsy can be procured in 15 pediatric cases and 60 adult cases. A slight female preponderance was noted with an M: F ratio of 1:1.2. (Table 1).

Out of total 91 cases of solid tumors bone marrow showed fragments in $71.4 \%$ cases (65 cases). Remaining 26 cases were hemodilutedwithout any bone marrow elements of which 18 showed metastatic tumor cells and were considered adequate while 8 cases were considered as inadequate.Out of 65 cases where the fragments are seen, there were 30 cases which showed normocellular fragments, 15 were hypercellular and 20 cases were hypocellular. Biopsy was present in 60 cases of these 65 cases and correlated well in relation to cellularity.

In adults 27 cases out of 71 cases (38.02\%) showed metastatic tumor deposits in bone marrow while 6 pediatric cases out of 20 were positive for metastasis (30\%). Both bone marrow aspirate and biopsy were positive in 25 cases (75.8\%) while 6 cases $(18.2 \%)$ showed tumor deposits only on aspirate. Isolated BM biopsy was positive only in two cases (6\%). Diffuse involvement of bone marrow was seen only in 5 cases and rest all showed focal tumor deposits.

Pediatric Cases: - Patients age ranged from 6 month to 12 years in 6 cases. The male to female ration was 1:1. Maximum number of cases were of Ewing's sarcoma (9\%) followed by rhabdomyosarcoma (6.1\%) and Neuroblastoma (3\%). Only two pediatric cases show clinical features suspicious of metastasis and both cases were of Ewing's sarcoma (ES) (Table 2).

Most common presentation was weakness and pallor with peripheral smears showing anemia (1case) and pancytopenia (1 case). One case of ES with pancytopenia also showed nucleated red blood cells in peripheral smear. Peripheral smear from the case of neuroblastoma does not show any abnormality and bone marrow was performed for routine staging purpose.

Adult Cases: Patients age ranged from 25 years to 75 years. The male to female ratio was 1:1.3. Maximum number of cases was of carcinoma of lung, including both small and non small cell type(27.3\%) (Fig. 1),followed by carcinoma of breast $(21.2 \%)$, Ovary $(9.1 \%)$, and prostate $(9.1 \%)$. One case each of carcinoma of stomach, gall bladder and esophagus (small cell carcinoma) were also seen metastasizing to marrow ( $3 \%$ each) (Fig. $1 \& 2$ ).

There were 2 cases where primary could not be found and the case was labeled as malignancy of unknown origin. Out of these two cases, one case showed bilateral adrenal metastasis and a primary from lung was suspected. In other case metastatic adenocacinoma was identified but site of origin could not be fixed. (Table 3 ).

Out of total 33 cases, 31 patients already had a known primary and presented with symptoms related to primary malignancies. Only two cases were primarily diagnosed as metastasis on bone marrow examination and presented with complaints related to BM suppression. On further workup, one case showed primary in breast and in other case ovary was found to be primary site of malignancy. In both these cases, peripheral smear findings showed leukoerythroblastic picture. The most common symptoms related to bone marrow suppression were weakness and easy fatigability due to anemia. Three cases presented with fever possibly due to infections secondary to leucopenia (Table 4).

The most common peripheral smear findings for which bone marrow evaluation was performed were isolated thrombocytopenia (36.4\%) followed by isolated anemia $(30.3 \%)$ and pancytopenia $(30.3 \%)$. A total of 10 cases $(30.3 \%)$ showed leukoerythroblastic picture on peripheral smear with presence of nucleated RBC's and immature forms of neutrophils. (Table 5).

\section{Discussion}

Bone marrow is one of the important sites of metastasis of solid tumors and is diagnosed using aspiration or biopsy. These two techniques complement each other and should be performed simultaneously. BM involvement is rare 
Table 1: Patient distribution by age:-

\begin{tabular}{|c|c|c|c|}
\hline & Number of Cases & Positive & Negative \\
\hline Peadiatric group & 20 & 6 & 14 \\
\hline Adult group & 71 & 27 & 44 \\
\hline Total number & 91 & 33 & 58 \\
\hline
\end{tabular}

Table 2: Paediatric cases with peripheral smear findings:

\begin{tabular}{|c|c|c|c|c|c|}
\hline Sr. No. & Age $(\mathrm{yrs}) / \mathrm{sex}$ & Primary Diagnosis & Primary Site & Indication for BME & Peripheral smear \\
\hline 1 & $10 / \mathrm{F}$ & Ewing's & Tibia & Staging & Normal \\
\hline 2 & $10 / \mathrm{M}$ & Ewing's & Femur & R/O mets & Anemia \\
\hline 3 & $3 / \mathrm{F}$ & Ewing's & Shoulder & R/O mets & PCP \\
\hline 4 & $0.5 / \mathrm{M}$ & Neuroblastoma & adrenal & Staging & Normal \\
\hline 5 & $3 / \mathrm{F}$ & RMS & Mediastinal & Staging & Normal \\
\hline 6 & $12 / \mathrm{M}$ & RMS & Orbit & Staging & Normal \\
\hline
\end{tabular}

Table 3: Adult cases with abnormal hematological findings in peripheral smear:

\begin{tabular}{|c|c|c|c|c|c|}
\hline Sr. No. & Age (yrs)/sex & Primary Diagnosis & Primary Site & Indication for BME & Peripheral smear \\
\hline 1 & $60 / \mathrm{M}$ & $\begin{array}{l}\text { Squamous cell } \\
\text { carcinoma }\end{array}$ & Lung & Staging & Thrombocytopenia \\
\hline 2 & $45 / \mathrm{M}$ & $\begin{array}{l}\text { Squamous cell } \\
\text { carcinoma }\end{array}$ & Lung & To rule out metastasis & Anemia and Thrombocytopenia \\
\hline 3 & $60 / \mathrm{M}$ & $\begin{array}{l}\text { Squamous cell } \\
\text { carcinoma }\end{array}$ & Lung & Staging & Pancytopenia \\
\hline 4 & $57 / \mathrm{M}$ & $\begin{array}{l}\text { Squamous cell } \\
\text { carcinoma }\end{array}$ & Lung & To rule out metastasis & Anemia and Thrombocytopenia \\
\hline 5 & $50 / F$ & Adenocarcinoma & Lung & To rule out metastasis & Thrombocytopenia \\
\hline 6 & $61 / \mathrm{M}$ & Adenocarcinoma & Lung & To rule out metastasis & Thrombocytopenia \\
\hline 7 & $54 / \mathrm{M}$ & Adenocarcinoma & Lung & To rule out metastasis & Pancytopenia \\
\hline 8 & $52 / \mathrm{M}$ & Adenocarcinoma & Lung & To rule out metastasis & Thrombocytopenia \\
\hline 9 & $57 / \mathrm{M}$ & Adenocarcinoma & Lung & To rule out metastasis & Pancytopenia \\
\hline 10 & $51 / F$ & Adenocarcinoma & Breast & To rule out metastasis & Anemia \\
\hline 11 & $55 / F$ & Adenocarcinoma & Breast & To rule out metastasis & Pancytopenia \\
\hline 12 & $50 / F$ & Adenocarcinoma & Breast & To rule out metastasis & Anemia and Thrombocytopenia \\
\hline 13 & $53 / F$ & Adenocarcinoma & Breast & To rule out metastasis & Pancytopenia \\
\hline 14 & $43 / \mathrm{F}$ & Adenocarcinoma & Breast & To rule out metastasis & Pancytopenia \\
\hline 15 & $50 / F$ & Adenocarcinoma & Breast & To rule out metastasis & Leukoerythroblastic picture \\
\hline 16 & $51 / F$ & Adenocarcinoma & Breast & $\begin{array}{l}\text { Leukoerythroblastic } \\
\text { picture }\end{array}$ & $\begin{array}{l}\text { Thrombocytopenia with } \\
\text { Leukoerythroblastic picture }\end{array}$ \\
\hline 17 & 70/M & Adenocarcinoma & Prostate & To rule out metastasis & Anemia and Thrombocytopenia \\
\hline 18 & 70/M & Adenocarcinoma & Prostate & To rule out metastasis & Anemia \\
\hline 19 & $65 / \mathrm{M}$ & Adenocarcinoma & Prostate & To rule out metastasis & Thrombocytopenia \\
\hline 20 & $55 / F$ & Adenocarcinoma & Ovary & To rule out metastasis & Anemia and Thrombocytopenia \\
\hline 21 & $60 / F$ & Adenocarcinoma & Ovary & To rule out metastasis & Pancytopenia \\
\hline 22 & $63 / F$ & Adenocarcinoma & Ovary & $\begin{array}{l}\text { Leukoerythroblastic } \\
\text { picture }\end{array}$ & $\begin{array}{l}\text { Thrombocytopenia with } \\
\text { Leukoerythroblastic picture }\end{array}$ \\
\hline
\end{tabular}




\begin{tabular}{|c|c|c|c|c|c|}
\hline Sr. No. & Age (yrs)/sex & Primary Diagnosis & Primary Site & Indication for BME & Peripheral smear \\
\hline 23 & $63 / F$ & $\begin{array}{c}\text { Squamous cell } \\
\text { carcinoma }\end{array}$ & Esophagus & To rule out metastasis & Anemia \\
\hline 24 & $25 / F$ & Adenocarcinoma & Stomach & To rule out metastasis & Pancytopenia \\
\hline 25 & $75 / F$ & Adenocarcinoma & Gallbladder & To rule out metastasis & Anemia and Thrombocytopenia \\
\hline 26 & $60 / F$ & Adenocarcinoma & $\begin{array}{c}\text { Malignancy } \\
\text { of unknown } \\
\text { origin }\end{array}$ & To rule out metastasis & Pancytopenia \\
\hline 27 & $55 / M$ & Adenocarcinoma & $\begin{array}{c}\text { Malignancy } \\
\text { of unknown } \\
\text { origin }\end{array}$ & To rule out metastasis & Panch \\
\hline
\end{tabular}

Table 4: Distribution of clinical profile of patients:

\begin{tabular}{|l|c|c|c|c|}
\hline Type of malignancy & Positive cases & Male & Female & $\begin{array}{c}\text { Symptoms related to bone } \\
\text { marrow suppression }\end{array}$ \\
\hline PEDIATRIC CASES & & & & 2 \\
\hline Ewing's sarcoma & 3 & 1 & 1 & 0 \\
\hline Rhabdomyosarcoma & 2 & 1 & 0 & 0 \\
\hline Neuroblastoma & 1 & 3 & 3 & 2 \\
\hline Total pediatric cases & 6 & & & \\
\hline ADULT CASES & & 4 & 1 & 5 \\
\hline Lung- Non small cell carcinoma & 5 & 4 & 0 & 4 \\
\hline Lung- small cell carcinoma & 4 & 0 & 7 & 5 \\
\hline Breast & 7 & 3 & 0 & 3 \\
\hline Prostate & 3 & 0 & 3 & 2 \\
\hline Ovary & 3 & 0 & 1 & 1 \\
\hline Esophagus & 1 & 0 & 1 & 1 \\
\hline Stomach & 1 & 0 & 1 & 1 \\
\hline Gall bladder & 1 & 1 & 1 & 2 \\
\hline Malignancy of unknown origin & 2 & $\mathbf{1 2}$ & $\mathbf{1 5}$ & \\
\hline Total adult cases & $\mathbf{2 7}$ & $\mathbf{1 5}$ & $\mathbf{1 8}$ & \\
\hline Total of all cases & & & \\
\hline
\end{tabular}

Table 5:Distribution of hematological profiles of patient:

\begin{tabular}{|c|c|c|c|c|c|}
\hline Type of malignacy & Total cases & Pancyto- penia & Anemia & $\begin{array}{l}\text { Thrombo- } \\
\text { cytopenia }\end{array}$ & $\begin{array}{c}\text { Leukoerythroblastic } \\
\text { reaction }\end{array}$ \\
\hline \multicolumn{6}{|l|}{ PEDIATRIC CASES } \\
\hline Ewing's sarcoma & 3 & 1 & 1 & 0 & 1 \\
\hline Rhabdomyosarcoma & 2 & 0 & 0 & 0 & 0 \\
\hline Neuroblastoma & 1 & 0 & 0 & 0 & 0 \\
\hline Total pediatric cases & 6 & 1 & 1 & 0 & 1 \\
\hline \multicolumn{6}{|l|}{ ADULT CASES } \\
\hline $\begin{array}{l}\text { Lung- Non small cell } \\
\text { carcinoma }\end{array}$ & 5 & 2 & 1 & 3 & 2 \\
\hline $\begin{array}{l}\text { Lung- small cell } \\
\text { carcinoma }\end{array}$ & 4 & 1 & 2 & 3 & 0 \\
\hline Breast & 7 & 3 & 2 & 1 & 3 \\
\hline Prostate & 3 & 0 & 2 & 2 & 1 \\
\hline Ovary & 3 & 1 & 1 & 1 & 1 \\
\hline
\end{tabular}




\begin{tabular}{|l|c|c|c|c|c|}
\hline Type of malignacy & Total cases & Pancyto- penia & Anemia & $\begin{array}{c}\text { Thrombo- } \\
\text { cytopenia }\end{array}$ & $\begin{array}{c}\text { Leukoerythroblastic } \\
\text { reaction }\end{array}$ \\
\hline Esophagus & 1 & 0 & 1 & 0 & 0 \\
\hline Stomach & 1 & 1 & 0 & 0 & 1 \\
\hline Gall bladder & 1 & 0 & 0 & 1 & 0 \\
\hline $\begin{array}{l}\text { Malignancy of } \\
\text { unknown origin }\end{array}$ & 2 & 1 & 0 & 1 & 1 \\
\hline Total adult cases & $\mathbf{2 7}$ & $\mathbf{9}$ & $\mathbf{9}$ & $\mathbf{1 2}$ & $\mathbf{9}$ \\
\hline Total of all cases & $\mathbf{3 3}$ & $\mathbf{1 0}$ & $\mathbf{1 0}$ & $\mathbf{1 2}$ & $\mathbf{1 0}$ \\
\hline
\end{tabular}

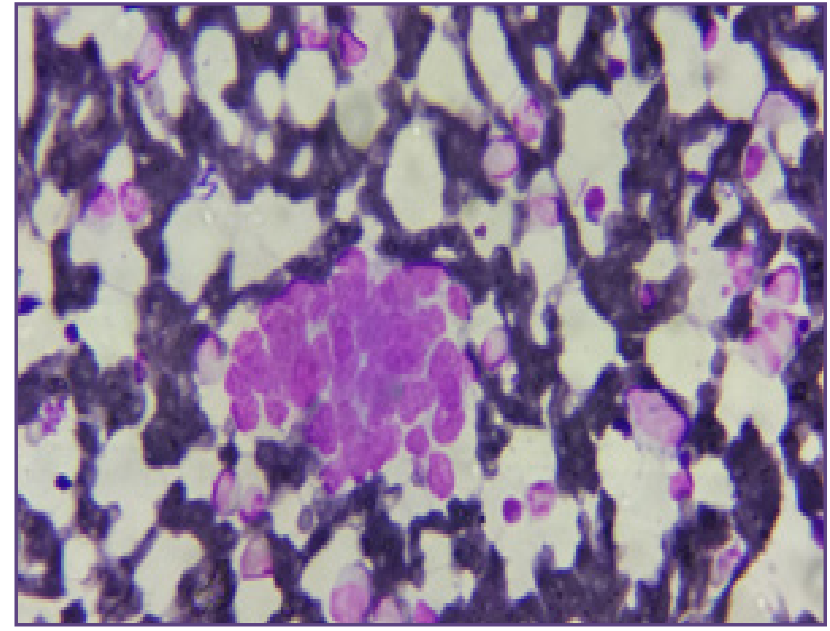

Fig. 1: Small cell carcinoma metastasis from oesophagus in bone marrow (MGG stain low power).

however results in various complications attributable to cytopenias such as bleeding, recurrent infections and symptoms related to anemia ${ }^{[4]}$ Bone marrow aspiration and biopsy is the most sensitive, easiest cheapest and least time consuming procedure for the diagnosis of clinically suspected bone -marrow involvement..$^{[4,7,12]}$

Chemotherapeutic agents also lead to various degrees of cytopenias thus adding to the worse outcome of disease. Magnetic resonance imaging can give a clue for BM metastasis but confirmation is to be done by aspiration or biopsy. ${ }^{[6]}$

Bone marrow examination is easy and cost effective procedure with rapid diagnosis and if positive, is confirmatory.

All tumors that can gain access to blood can metastasize to marrow; however cancers of prostate, breast, and lungs are the most common tumors showing marrow involvement.

There are many studies in western and Indian literature demonstrating bone marrow metastasis in non hematological malignancies: ${ }^{[8-12][7}$

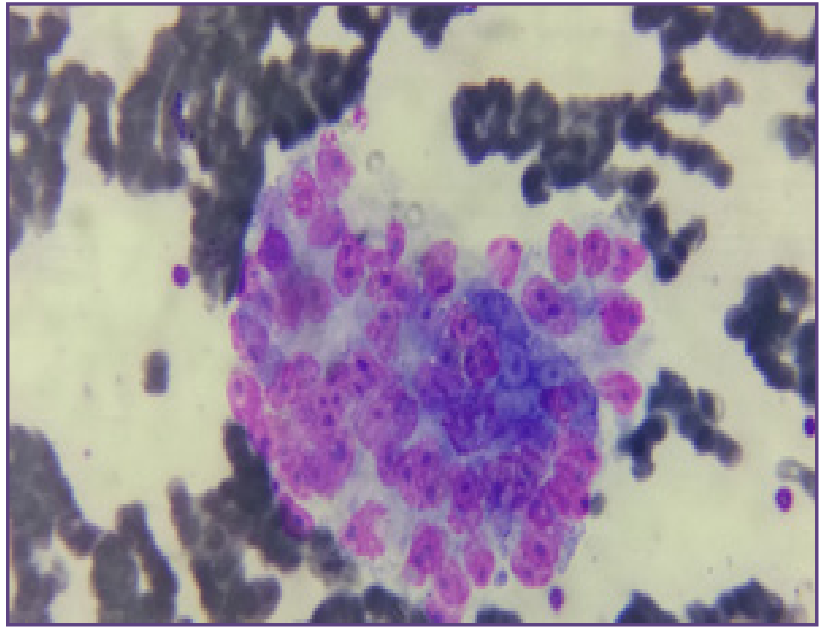

Fig. 2: Matastasis of adenocarcinoma from lung (MGG stain, high power).

According to literature, all malignancies can metastasize to bone marrow, but the common ones are malignancies of prostate, breast, lungs. In many instances, however, primary site of origin of primary cannot be ascertained. In our study, we found that the most common cancer to metastasize to marrow in females was breast and lung cancer in males which is not different from many other studies coated in literature which shows same results. ${ }^{[7]}$ But other studies shows prostate as the most common primary. ${ }^{[2]}$ In this study, prostate cancer stood $3^{\text {rd }}$ after lung adenocarcinoma, breast and lung small cell carcinoma, possibly because of more lung cancer patients catering to our hospital and is in concordance to study done by few. ${ }^{12}$

In childrens, Ewing's sarcoma/PNET was the most common tumor to metastasize which is similar to the few studies in the literature. ${ }^{[9]}$ We also found 2 cases of rhabdomyosarcoma and one case of neuroblastoma in children. One case of primary small cell carcinoma of esophagus showed tumor cells in aspirate, which itself is a rare diagnosis. We found aspirate to be more sensitive than biopsy in picking up of malignant cells with only 2 false negative cases (one of lung and other of breast) 
while bone marrow biopsy was falsely negative in 6 cases. The probable reason was inadequate length of the biopsy because in cases where the infiltration is focal, small foci of metastases can be easily missed.So, bone marrow biopsy should be performed along with aspiration in order to reduce the false negative cases and appropriate staging of the case.

Present study reveals many hematological abnormalities. Most common was isolated thrombocytopenia followed by pancytopenia and anemia. Leukoerythroblastic picture was seen in $30.3 \%$ of cases and in our study also it was an important indicator of metastasis which is in concordance with other studies in literatue ${ }^{[1,11,13]}$ There were no specific hematologic lineage changes in bone marrow aspirate smears which can suggest the possible metastasis other than the leukoerythroblastic picture in peripheral smears. Bone marrow should be performed in any known case of solid tumors with unexplained cytopenias or presence of leukoerythroblastic blood picture. However, few studeis showed anaemia as a most comman hematological abnormality during metastasis in bone marrow. ${ }^{[14,15]}$

Newer techniques are used to demonstrate marrow involvement in early stage disease for this immunohistochemistry, flow cytometry and PCR techniques are used. These techniques indicate a greater frequency of tumor infiltration than has been evident, from standard histological methods. ${ }^{[14,16,17,18]}$

Bone marrow aspiration and trephine biopsy are relatively sensitive technique for detecting bone marrow infiltration by metastatic tumors should be used in combination for increasing its efficacy: ${ }^{[19]}$

\section{Conclusion}

Bone marrow aspiration is an effective and cheap method for evaluating solid tumors metastatic to bone marrow. More over a clue to the primary site can also be suggested if the primary is unknown and metastatic lesions are detected in the bone marrow. Thrombocytopinia, anemia \&leucoerythroblastic picture can be correlated with marrow metastatic in suspected cases.Hence it is concluded that aspiration of bone marrow provides an easy and quick way of detectionof marrow involvement, however, biopsy with immunohistochemical and / or molecular techniques may be needed in case of microscopical tumor metastasis.

\section{References}

1. Sharma S, Murari M. Bone marrow involvement by metastatic solid tumors. Indian Journal Pathology \& Microbiology 2003; 46(3):382-84.
2. Sambit KM, Dash S. Bone marrow metastasis in solid tumors Indian Journal Pathology \& Microbiology 2003; 46(4):613-16

3. Kaur G, Basu S, Kaur P, Sood T. Metastatic bone marrow tumors: Study of nine cases and review of the literature. Journal of Blood Disorder and Transfusion 2011;2:110.

4. Bain BJ, Clark DM, Wilkins BS, Lampert IA. Metastatic tumors. In: Bain BJ, Clark DM, Wilkins BS, editors. Bone Marrow Pathology. 3rd ed. England, Malden, MA: Blackwell Science, Bon Oxford; 2001. p. 430-61

5. Valdes-Sanchez M, Nava-Ocampo AA, Palacios-Gonzalez RV, Perales-Arroyo A, Medina-Sanson A, Martinez-Avalos A. Diagnosis of bone marrow metastases in children with solid tumors and lymphomas. Aspiration, or unilateral or bilateral biopsy? Archives of Medical Research. 2000;JanFeb; 31(1) :58-61.

6. Takemoto C, Nishiuchi R, Endo C, Oda M, Seino Y. Comparison of two methods for evaluating bone marrow metastasis of neuroblastoma: reverse transcriptionpolymerase chain reaction for tyrosine hydroxylase and magnetic resonance imaging. Pediatrics Internasional. 2004; Aug, 46 (4) :387-93.

7. Kilickap S, Erman M, Dincer M, Aksoy S, Hakan H, Yalcin $\mathrm{Y}$ et. al. Bone marrow metastasis of solid tumors: clinicopathological evaluation of 73 cases. Turkish Journal of Cancer 37(3):85-88

8. Ozkalemkas F, Ali R, Ozkocaman V, Ozcelik T, Ozan U, Ozturk $\mathrm{H}$, et al. The bone marrow aspirate and biopsy in the diagnosis of unsuspected nonhematologic malignancy: A clinical study of 19 cases. BMC Cancer 2005;5:144

9. Mishr P. Das S, Kar R, Jacob SE, Basu D. Nonhaemoatopoietic malignancies metastasing to the bone marrow: A 5 year record based descriptive study from a tertiary care centre in south India. INdian Journal of CANCER 2014: 51(1) ;30-34.

10. Atac B, Lawrence C, Goldberg SN. Metastatic tumors .The complementary role of marrow aspirate and biopsy. American Journal of the medical Sciences. 1991; Oct 302(4):211-13

11. Sar R, Aydogdu I, Ozen S et al .Metastatic bone marrow tumors: A report of six cases and review of literature. Hematologia 2001; 31(3):215-23

12. Singh G, Krause JR, Breitfeld V. Bone marrow involvement by metastatic tumors: for metastatic tumor: aspirate and biopsy. Cancer 1977 Nov, 40 (5):2317-21.

13. Chauhan K, Jain M, Grover S, Shukla P, Rusia U, Grover RK. Bone marrow metastisis in nonhematologic malignancies: Data from a cancer hospital. Clinical cancer Investigation journal 2016; 5 (2), 103-109.

14. MM Reid, JP Walls, A.G. Mc Guckin et al. Routine Histological compared with immunohistological 
examination of bone marrow trephine biopsy specimens in disseminated neuroblastoma. Journal of Clinical Pathology 1991: June 44(6); 483-86

15. Pangrahi R, Behera PK, Tripathy KP. Bone marrow involvement in Non hematological Disrorders-An Institutional Experience. IOSR Journal of Dental and Medical Sciences. 2017;April 16 (4); 51-53.

16. Clevenger, C. V., Khandewal, M., Stadtmauer, E., and Jardines, L. Detection of bone marrow breast carcinoma metastasis using multiparameter flow cytometry. Annals of the New York Academy of Sciences. 193 Mar 20; 677: 400-1.
17. Pelkey TJ, Frierson HF, Bruns DE. Molecular and immunological detection of circulating tumor cells and micrometastases from solid tumors. Clinical chemistry. 1996 Sep; 42(9):1369-81.

18. Raj, G. V., Moreno, J. G., and Gomella, L. G. Utilization of polymerase chain reaction technology in the detection of solid tumors. Cancer. 1998 Apr 15;82(8):1419-42.

19. Farah Moid, Louis De Palma Comparison of relative value of Bone marrow Aspirates and Bone marrow Trephine Biopsies in the Diagnosis of solid tumor metastasis and Hodgkin's lymphoma; Institutional Experience and literature review, Archives of Pathology and Laboratory. Medicine. 2005 Apr,. 129 (4); 497-501.

*Corresponding author:

Dr. Sandeep Ojha, Department of Pathology, Chirayu Medical College and Hospital Bhaisakhedi, Bhopal-Indore Highway, Near Bairagarh Bhopal (M.P.) India Phone: +91 7806090888

Email: drsandy0582@gmail.com

Financial or other Competing Interests: None. 